\title{
ENTREVISTA COM ANA LUÍSA AMARAL, POETA E PROFESSORA DA FACULDADE DE LETRAS DA UNIVERSIDADE DO PORTO
}

Nicole Guim de Oliveira ${ }^{1}$

RESUMO: Entrevista com Ana Luísa Amaral, realizada durante a vigência da Bolsa de Estágio de Pesquisa no Exterior, concedida pela Fundação de Amparo à Pesquisa do Estado de São Paulo (FAPESP).

Ana Luísa Amaral, 61 anos, é uma escritora portuguesa, autora de dezesseis obras de poesia, dentre elas Minha Senhora de Quê (1990), Imagias (2002), Vozes (2011) e Escuro (2014). É autora também do romance Ara (2013) e da obra dramática Próspero Morreu (2011). Além disso, Ana Luísa Amaral é tradutora e professora de Literatura e Cultura Inglesa e Americana na Faculdade de Letras da Universidade do Porto. A entrevista foi concedida no dia 6 de fevereiro de 2017, quando a poeta e professora ministrava o curso “A poesia tem sexo?", que teve lugar na Biblioteca Almeida Garrett, no Porto.

[Nicole Guim de Oliveira] Vou começar pelo título do seu curso atual: a poesia tem sexo?

[Ana Luísa Amaral] Pois não sei. A poesia tem sexo? Não sei, quer dizer... O título desse curso é um título provocatório porque... e sobretudo aquilo que eu tento nesse curso, eu tento também equacionar essa questão, uma questão que tem me preocupado de uns anos pra cá. Uma questão que tem vindo me ocupar, melhor dizendo, não é exatamente uma preocupação. Preocupações tenho outras, que têm a ver com a maneira como o fenômeno poético se inscreve no campo do social e do político. Isso é uma preocupação pra mim. Agora, tenho me vindo a ocupar, que são coisas um bocadinho diferentes do ponto de vista teórico dessa questão, de que se a poesia, se o texto, digamos assim, tem ou não tem sexo. Não digo gênero, digo sexo.

\footnotetext{
${ }^{1}$ Mestranda em Letras pela Universidade de São Paulo (USP).
} 


\section{[NGO] Sim, e por quê?}

[ALA] Porque acho que o politicamente correto, a determinada altura, foi erradamente utilizado. Eu sou, obviamente, a favor do politicamente correto. Mas, por exemplo, quando a partir dos anos 70 , início dos anos 80 , se começa a pensar a palavra gender como alternativa àquilo que sexo não conseguia dizer e, portanto, gender, ou melhor dizendo, gênero passa a significar a diferença sexual social, politicamente e culturalmente construída, que equivale naturalmente à desigualdade, eu acho que depois as instâncias institucionais apropriaram-se disso e, querendo ser politicamente corretas, acabaram por usar gênero em momentos que, para mim, gênero não tem nada que ser utilizado. Estou a pensar, por exemplo, em formulários, em que aparece gênero masculino e gênero feminino, quando eu acho que não é. É sexo masculino, sexo feminino, outro. Porque nós temos vários sexos, há vários sexos. A minha proposta é que seja sexo masculino, sexo feminino, outro, e prefere não dizer. Se ninguém lhe pergunta se tem olhos verdes, olhos azuis, ou castanhos, por que é que se há de perguntar qual o sexo? Por que é que o sexo tem de ser tão determinante, não é? Gênero, para mim, tem conotações diversas, naturalmente. Tem a ver com papéis. Ora, a poesia, por definição, trabalha com papéis. Portanto, perguntar se a poesia tem gênero eu acho que é uma pergunta mais fácil, digamos assim, do que perguntar se a poesia tem sexo. Porque gênero, tendo a ver com a construção de papéis, então, à poesia sempre foi possível mimetizar papéis femininos.

\section{[NGO] Como isso é possível?}

[ALA] Estou a pensar não só nos trovadores, nos cancioneiros, mas estou a pensar em um autor como Lobo Antunes, que tem tanta crônica... estou a pensar nas crônicas de Lobo Antunes em que ele sabe tão bem, tão bem, vestir-se de mulher, ou melhor, travestir-se, melhor dizendo, de mulher. Isso é gênero, a meu ver, não é sexo. O que eu quero dizer com isso é que quando eu penso nos cancioneiros, quando eu penso em Lobo Antunes, quando eu penso numa série de homens que escrevem papéis femininos, o que está ali exibido é um estereótipo, sempre. É o estereótipo da mulher. É o velho problema de se perguntar: o que é um travesti? Não sou eu que pergunto, a própria Butler já faz essa pergunta em Gender Trouble. Quando pergunto aos meus alunos o que é um travesti, eles me respondem que é um homem que se veste de mulher. Eu lhes digo: pois, mas, estão aqui vinte mulheres, estão todas vestidas da mesma maneira? O que é vestir-se de mulher? 


\section{[NGO] O que é ser mulher, afinal, não é?}

[ALA] O que é ser mulher? Com certeza. Beauvoir já tinha colocado essa questão. Eu acho essa questão interessante, aliás, eu tenho escrito sobre isso. Essa questão tem a ver com o gênero. Quando Simone de Beauvoir diz "não nascemos mulheres, tornamo-nos mulheres”, aliás, isso pode ser lido de duas maneiras, ou "não nascemos mulheres, tornamo-nos mulheres", então eu estou a incluir-me nesse plural, ou "ninguém nasce mulher, torna-se mulher", e este ninguém aplica-se tanto a machos como a fêmeas. Quer dizer, um macho pode tornar-se mulher, não é, porque, sendo esse conceito de mulher todo um conjunto de estereótipos.

\section{[NGO] É o que Judith Butler faz em Problemas de Gênero.}

[ALA] Sim, exatamente. Por que é que os travestis, em sua esmagadora maioria, têm um tipo de vestuário, um tipo de maquiagem, que respondem a um estereótipo de um feminino, de um imaginário ou de uma fantasia. É a mesma coisa que fizeram os modernistas, não é? Armando Cortes Rodrigues, por exemplo... “As minhas mãos são esguias/ são fusos brancos d'arminho", não é? Ou Mário de Sá-Carneiro, "a minha obra representa zebradamente entre luas amarelas aquilo que eu quisera ser fisicamente: essa rapariga estrangeira de unhas polidas, doida e milionária...”’, Ora... Provavelmente há muito mais mulheres a não polirem as unhas do que a polirem as unhas, não é? Portanto, voltando à nossa questão anterior, "a poesia tem sexo?”, é uma provocação, no fundo, e é também um convite para as pessoas pensarem um bocadinho em, mais do que vermos se há traços sexuados no texto literário, seria determonos sobre todo o sistema construído já de desigualdades, de discriminações, que sustenta, por assim dizer, a nossa sociedade. E, então, a questão do sexo na poesia, a meu ver, teria até bastante mais a ver com a recepção do que propriamente com a produção. Ou seja, como é que eu leio um poema? Por que é que ao ler um poema, a questão do sexo do poeta ou da poeta, ou melhor, a questão do sexo de quem escreve não me passa despercebida? Por que é que eu, se ler um poema escrito por uma mulher, tenho tendência a lê-lo de uma determinada maneira e associar a ele determinados aspectos, que são obviamente devedores do social, ao passo que, se eu leio um poema escrito por um homem, esses traços são pura e simplesmente

\footnotetext{
${ }^{2}$ Referência ao poema "A mim própria de há dois annos", de Violante de Cysneiros, pseudônimo do poeta Armando Côrtes-Rodrigues.

${ }^{3}$ Referência à Correspondência com Fernando Pessoa, de Mário de Sá-Carneiro.
} 


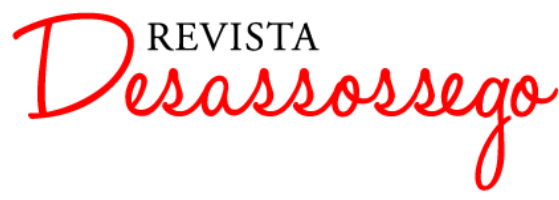

DESASSOSSEGO 16 | DEZ/2016 | ISSN 2175-3180

DOI: http://dx.doi.org/10.11606/issn.2175-3180.v8i16p133-140

elididos e aquilo cai na categoria de um neutro? Como bem demonstrou Maria Isabel Barreno, não deixa de ser um falso neutro, não é?

[NGO] Nesse sentido, as teorias feministas, de acordo com Linda Hutcheon, são parte da análise literária. E por que é que a gente tende a utilizar as teorias feministas como base de análise sempre para mulheres poetas?

[ALA] Sim, mas eu posso usar também as teorias feministas para analisar textos escritos por homens, embora não seja nossa tendência fazê-lo. Por exemplo, eu dei a minha primeira sessão semana passada na biblioteca Almeida Garrett e, um dos textos que lhes passei, foi uma crítica de Miguel Real a um livro de Mário de Carvalho. Esse texto, de forma a elogiar um livro de Mário de Carvalho, Ronda das mil belas em frol, precisa de dizer coisas como "a mulher não é, nestes contos, um objeto de prazer do homem, como era a Amélia para o Padre Amaro [...], como era uma vexada ou opressa a Maria Teresa Horta". E diz mais, "É este, talvez, o grande contributo destes contos para a historiografia do sexo na literatura portuguesa: o de fazer ver que o corpo da mulher também é sujeito e há muito deixou de ser objeto. Um salto literário pós-Maria Teresa Horta”. E, ainda, "Não está aqui a raiva explosiva e insurrecta de Maria Isabel Barreno, Maria Velho da Costa e Maria Teresa Horta". Está a dizer que, pela primeira vez, um homem fala no desejo feminino, ou, pela primeira vez, se faz ver na literatura que o corpo da mulher também é sujeito. Mas, então, o que é feito de livros como Minha Senhora de Mim (1971), e o que é feito do que veio antes disso, como Natália Corrêa, por exemplo? O que é feito das Novas Cartas Portuguesas (1972)? Quer dizer... o que é feito de tudo que foi produzido nos anos 60? Por muito que eu gosto do livro de Mário de Carvalho, mas a justificação, que é a menorização de tudo aquilo que as mulheres escreveram, é curiosa.

[NGO] Mas é isso, não é, parece que só quando um homem fala é legítimo. Parece que quando uma mulher fala não é legítimo.

[ALA] Claro, como é possível dizer que em 2016 pela primeira vez o corpo da mulher é sujeito, não é, e, em 1972, nós tínhamos “freira não copula/ mulher parida e laureada/

\footnotetext{
4 Trechos retirados da crítica de Miguel Real ao livro Ronda das mil belas em frol (2016), de Mário de Carvalho, publicada em 13 de outubro de 2016.
} 


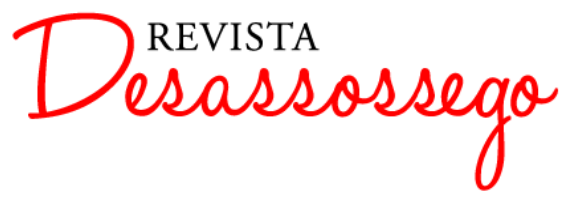

DESASSOSSEGO 16 | DEZ/2016 | ISSN 2175-3180

DOI: http://dx.doi.org/10.11606/issn.2175-3180.v8i16p133-140

escreve mas não pula/ (e muito menos se o fizer a três)" "5 , e por aí afora. Ou temos um texto como “A Paz", não é, que é um texto das Novas Cartas Portuguesas (1972) sobre a masturbação feminina. Portanto, como é possível que se diga que pela primeira vez o corpo da mulher é sujeito em 2016. Quer dizer... Esse texto de Miguel Real tem sexo, compreende? E isso é a recepção. Até porque, assim, eu que sou poeta sei, não é, quando escrevemos, escrevemos para nós. Quando escrevo, escrevo para mim, escrever é um ato solitário. Pensar também, um pouco, não é? Mas, quando eu escrevo, escrevo para mim, não estou a pensar em quem me vai ler. Mal de mim, claro, mal de mim estava eu se escrevesse poesia a tentar responder a um possível leitor ou leitora, não é? Portanto, todo poema... Eu tenho um poema que diz isso, "todo poema é sobre aquele que sobre ele escreve", pronto. Quer dizer, depois do poema escrito, há a necessidade de o mostrar, há a necessidade de o tornar público. Isso pode ser um gesto mais reduzido, tornar público a dois, ou três, ou quatro, ou pode ser um gesto mais alargado, e aí temos a publicação de livros, não é?

\section{[NGO] Sim, a escrita é um ato solitário, mas com todo eco do que você fez e do que} já foi escrito antes...

[ALA] Claro, e as duas coisas não se anulam. O que eu quero dizer é que quando a gente escreve não pensa no leitor, agora, todo o mundo e tudo o que está a volta de mim está implicado. Todo o mundo, quando se diz, não é o todo mundo do português do Brasil... não é toda a gente, é o mundo inteiro. O mundo inteiro é implicado na minha escrita, com certeza, e o próprio fato de eu ser mulher, o próprio fato de eu ser mãe, quer dizer... toda uma série de traços, naturalmente, que fazem parte de mim. Agora, quando eu estou a escrever eu não escrevo a pensar no modo como vou ser lida. Escrevo por necessidade, escrevo porque preciso de escrever. Tal como preciso beber água, quando tenho sede de escrita, eu tenho de escrever. É uma necessidade. Portanto, sendo uma necessidade, ela serve-me em primeiro lugar a mim. Depois de o poema estar feito, eu mostro-o. Preciso de mostrar, preciso de o partilhar, porque acho que a arte é partilhar, é comunicação. Mas esse é o segundo momento. E depois há um terceiro momento, e é aqui que eu quero convidar as pessoas a pensarem um bocadinho, que é quando o poema chega ao outro lado, e outros olhos o leem, o veem e

\footnotetext{
${ }^{5}$ Referência à Terceira Carta I, da obra Novas Cartas Portuguesas (1972), de Maria Isabel Barreno, Maria Velho da Costa e Maria Teresa Horta.

${ }^{6}$ Referência ao poema "Psicanálise da Escrita", da obra Vožes (2011), de Ana Luísa Amaral.
} 


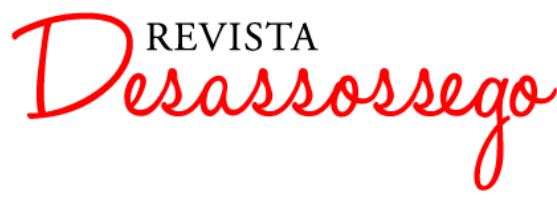

DESASSOSSEGO 16 | DEZ/2016 | ISSN 2175-3180

DOI: http://dx.doi.org/10.11606/issn.2175-3180.v8i16p133-140

o "escrevem” à sua própria maneira. E, portanto, esse terceiro momento, que é o momento em que o poema me é devolvido, eu acho que esse pode ser profundamente sexuado. Entende? Quer dizer... Eu tenho alguns poemas escritos à minha filha, por exemplo, e por que é que esse traço é um traço referido pela crítica, tantas vezes? E por que é que os poemas de Vasco Graça Moura, "sonetos às minhas filhas", não são pensados tendo em linha de conta o fato de Vasco Graça Moura ser um homem? Por que é que o meu sexo tem de ser considerado? E o que eu pergunto é... Leituras feministas, inclusivamente, da minha poesia a partir do fato de eu ser mulher?

\section{[NGO] E mãe. Afinal, sua filha nunca quebrou a tigela ${ }^{7}$.}

[ALA] E mãe, exatamente, minha filha nunca quebrou a tigela... Mulher, mãe, e de falar de cozinha, por exemplo, não é? Mas também há homens que falam de cozinha. É curioso... Falei nisso na primeira sessão que dei de “A poesia tem sexo?”... É uma questão também que me ocupa um pouco, em que eu penso bastante... Não será que o espaço "feminino", entre aspas, porque é sempre o estereótipo, não é, só posso pensar daqui... Não será que o espaço do "feminino" é um espaço mais sedutor? Porque é o espaço que foi sempre, tradicionalmente, milenarmente, o espaço da alteridade? Portanto, é o espaço do outro, da outra, nesse caso...

\section{[NGO] Alteridade e confinamento...}

[ALA] Exatamente, confinamento. É o espaço que aos homens foi sempre, de alguma maneira, vedado, sob pena de eles se "feminizarem", não é, de ficarem mais "frageizinhos", então é um espaço muito apetecível de explorar. Para as mulheres, qual é o espaço do masculino? O que é a escrita masculina? Mas, se eu pensar quais são os espaços do feminino, em termos de estereótipo. Quais são? É o fechado, é o doméstico, é o privado, são os bordados, é a cozinha, são os filhos, etc. E agora, eu pergunto, por oposição, quais são os espaços masculinos estereotipados? É a política, são os discursos políticos, é a guerra... quer dizer, por que é que eu vou escrever sobre isso? Não me interessa. Entende? Porque esses temas são, por assim dizer, os visíveis, até porque são os temas públicos, eu acho que eles não oferecem tanta sedução, não são tão atrativos, digamos assim, quanto ao espaço

\footnotetext{
${ }^{7}$ Referência ao poema "A Verdade Histórica”, da obra Minha Senhora de Quê (1999), de Ana Luísa Amaral.
} 


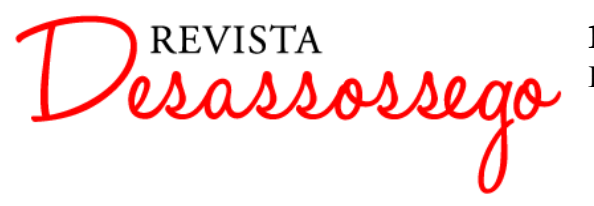

DESASSOSSEGO 16 | DEZ/2016 | ISSN 2175-3180

DOI: http://dx.doi.org/10.11606/issn.2175-3180.v8i16p133-140

psicossexual atribuído ao feminino. Então são essas questões que eu debato um bocadinho nos meus textos. Agora, não quer dizer que não haja poesia feminista, são coisas diferentes. E a poesia feminista faz-se quando há... Aliás, eu própria escrevi isso com Maria Irene Ramalho, o próprio gesto de roubar a palavra ao masculino já é um gesto feminista, não é? Eu posso falar de poesia feminista, por assim dizer, quando há um abertíssimo comprometimento... Sei lá, eu tenho poemas como "Carta a minha filha" e acho que esse poema é feminista.

\section{[NGO] Ou “A Carta”, de Escuro.}

[ALA] Sim, claro, "A Carta", de Mariana Alcoforado, de Escuro... Agora, por exemplo, quando Sophia de Mello Breyner Andresen escreve um poema como "25 de abril", "Esta é a madrugada que eu esperava/ o dia inicial inteiro e limpo" "... Eu tenho muita dificuldade em ler isso à luz das teorias feministas. A não ser que eu diga "Ah! Sophia de Mello Breyner Andresen era poeta e era mulher! Olha...”, mas isso é forçar uma leitura

\section{[NGO] Sim, mas o texto é que tem de dar abertura para a leitura feminista...}

[ALA] Claro, mas eu sempre defendi isso, afinal também sou crítica literária, não é? E eu acho que só, nesse caso, é que nos é possível... Quer dizer, eu acho que a literatura prevê sempre e sempre previu as teorias. Sempre se antecipou às teorias... Por isso é que me irrita tanto aquelas pessoas que são profundamente teóricas e que se atêm ao teórico, sabe, e depois constroem toda uma teoria e partir dali encaixam aquilo no texto, quando o texto tem de falar por si... E, por vezes, há textos que, ao meu ver são os melhores, são impossíveis de categorizar. Onde é que eu ponho Willian Blake? No Romantismo? Sim, mas ele é anterior ao Romantismo. Onde é que eu ponho as Novas Cartas Portuguesas? Compreende? É muito difícil colocá-los em escolas. Há textos que resistem às teorias, quer dizer... E um bom autor, um bom escritor resiste muito a ser confinado em teorias.

\footnotetext{
8 Poema "Um pouco só de Goya: Carta à minha filha", da obra Imagias (2002), de Ana Luísa Amaral.

9 Poema "25 de Abril", da obra O Nome das Coisas (1977), de Sophia de Mello Breyner Andresen.
} 
[NGO] Sempre penso isso sobre as Novas Cartas Portuguesas. Para quê confinar uma obra que só almejou a liberdade?

[ALA] Com certeza. Concordo em absoluto consigo. Não há necessidade. Bons escritores e boas obras resistem às teorias e às categorizações. Pronto, acho que é isso.

\section{REFERÊNCIAS BIBLIOGRÁFICAS:}

AMARAL, Ana Luísa. Ara. Porto: Sextante Editora, 2013. Escuro. Lisboa: Assírio \& Alvim, 2014. Imagias. Lisboa: Gótica, 2002. - Minha Senhora de Quê. Prefácio e posfácio de Maria Irene Ramalho de Sousa Santos. Lisboa: Quetzal Editores, 1999. . Próspero Morreu. Lisboa: Editorial Caminho, 2011. Vozes. Lisboa: Dom Quixote, 2011.

ANDRESEN, Sophia de Mello Breyner. O Nome das Coisas. Lisboa: Moraes Editores, 1977.

BARRENO, Maria Isabel; HORTA, Maria Teresa; COSTA, Maria Velho da. Novas Cartas Portuguesas. Lisboa, Editorial Futurama, 1972.

CYSNEIROS, Violante. A mim própria de há dois annos. In: Orpheu 2. Lisboa, 1915.

SÁ-CARNEIRO, Mário de. Correspondência com Fernando Pessoa. São Paulo: Companhia das Letras, 2004. 